\title{
Phytochemical Screening and Nutrient Analysis in Pulp Extract of Cucurbita Maxima
}

\author{
Keerthika $^{1}$, Mani Priya ${ }^{2}$ \\ ${ }^{1}$ Department of Biochemistry, ${ }^{2}$ Department of Microbiology, Saveetha medical college, Chennai, India \\ keerthibsc12[at]gmail.com, manipriyamedmic[at]gmail.com
}

\begin{abstract}
The pumpkin (cucurbita maxima) is a dicotyledonous vegetable, belonging to the cucurbitaceous family. The top pumpkin producing countries include India, California. Pumpkin is one of the most popular crops in the United states, about 1.5 billion pounds (680,000,00 kilograms) produced each year. Pumpkin (cucurbita maxima) has received considerable attention in recent years because of the nutritional and protective values of the pulp. The medicinal properties of Cucurbita maxima include anti-diabetic, antioxidant, anticarcinogenic, and anti-inflammatory effects. The objective of this study was to identify the phytochemicals and nutrient levels in the Cucurbita maxima pulp extracts. The extracts of Cucurbita maxima were subjected to preliminary screening. The Phytochemical screening of the Cucurbita maxima pulp extracts revealed the presence of polyphenols, alkaloids, flavanoids, terpenoids, glycosides and Tanins. The pulp is an excellent source of protein and also has pharmacological activites such as anti-diabetic, anti-inflammation activites and antioxidant effect. This is the context where appearance the concept of "Functional food" they are good source of calories, protein, minerals, fibre contribute in regulating cholesterol. Pumpkin pulp (cucurbita maxima) considered a poor man's vegetable, contain dietary antioxidants which provide bioactive mechanism to reduce free radical induced oxidative stress and probably play a role in the prevention of aging various disease associate with oxidative stress such as cancer, cardiovascular disease.
\end{abstract}

Keywords: Curcubita maxima, Phytochemicals, Antioxidant, Nutrient, Aqueous

\section{Introduction}

The plant kingdom is an important source of herbal drugs. Even in recent years, there has been an increasing awareness about the importance of medicinal plants. According to World Health Organization, medicinal plants would be the best source to synthesize drugs. Pumpkin is gourd-like squash belongs to genus Cucurbita and the family Cucurbitaceae. Pumpkins are considered to be a fruit and it contains 90 percent water. It is monoecious plant and it has both male and female flowers on the same plant. The pulp is characteristically flat and asymmetrically oval, and light green in color.

The nutritional profile of pumpkin pulp including carbohydrate, sugar, soluble insoluble fiber, mineral, vitamin, fatty, acid, amino acid and more. The study facilitates to utilize the low cost nutritious food. This present study increase the new varities of pumpkin pulp food. Most of the commercial vegetable available in the market are high in cost and also less nutrious. Pumpkin pulp serves as a good nutrious food and help in promoting good health.

The pumpkin has great economic potential for use both as a food and industrial crop. Pumpkin has health enhancing properties and could also be used for ecological balance it provide good ground cover (Mnzava et al..,1999). The present study was undertaken to evaluation of nutrients analysis of cucurbita maxima (pumpin) pulp.

\section{Materials and Methods}

Selection of raw material and procedure

Cucurbita maxima were obtained from different farm location in Trichy, Tamilnadu. The sample pumpkin rinsed with distilled water to avoid surface contamination.
The flesh of the fruit and the seed were separated using clean knife, silver spoon. The sample was meshed to a fine paste using mortar and pestle. It is sieved through stored in a air tight plastic container for analysis.

\section{Preparation of extract:}

Pumpkin pulps were dried with hot air oven. $\mathrm{NaOH}$ were added to this solution and heated and filtered to get the residue.

\section{Estimation of Minerals}

\section{Calcium}

Powdered sample was added to $\mathrm{NaOH}$, pahonreader and titrate on EDTA solution. Appearance of pale pink colour is the end point.

\section{Potassium}

Powdered sample was added to $1 \mathrm{~N}$ ammonium acetate. The colour was developed and using spectrophotometer.

Iron

Powdered sample was added Hcl, potassium per sulphate and potassium thiocynate. The colour was developed and using spectrophotometer.

\section{Estimation of Vitamins}

\section{Vitamin C}

Powdered sample was added starch. Then titrate with $\mathrm{K} 10_{3}$. Blue colour is the end point. 


\section{International Journal of Science and Research (IJSR) \\ ISSN (Online): 2319-7064}

Index Copernicus Value (2015): 78.96 | Impact Factor (2015): 6.391

\section{Vitamin A}

Powdered sample was added Isopropine alcohol and Heptain. Then taken for supernatant and added TCA. The colour was developed and using spectrophotometer.

\section{Vitamin E}

Powdered sample was added $\mathrm{NaOH}$,incubate for 6 hour. Then added distilled water, petroleum ether and phenopthalin. Continuosly heated the solution with dried and added to the phosphomaliphidic acid, ethanol. The colour was developed and using spectrophotometer.

\section{Estimation of carbohydrate}

Pumpkin pulp was added $\mathrm{Hcl}$ and heated for 3 hours. Added to sodium carbonate and diluted with water. Incubate for 24 hour and precipitate was formed. Anthrone reagent was added and boiled for few minutes. The colour was developed and using spectrophotometer.

\section{Estimation of protein}

Pumpkin pulps were added distilled water and incubate for 15 minutes. Then added standard solution and phenol reagent incubate for 30 minutes then colour was developed and using spectrophotometer.

\section{Estimation of fat}

Pumpkin pulp was added to ferric chloride acedic acid and $\mathrm{Hcl}$. Incubate for 20 minutes, then colour was developed and using spectrophotometer.

Identification of the plant constituents by phytochemical test

\section{Test for alkaloids}

$1 \mathrm{ml}$ of extract was added with dilute hydrochloric acid and it was filled using filter paper, the filtered extract were added with Wagner's reagent which was prepared by adding two drops of iodine in $2 \mathrm{ml}$ of potassium iodide solution. Formation of yellowish brown precipitate indicates the presence of alkaloids.

\section{Test for phenols}

$0.5 \mathrm{ml}$ of $\mathrm{Fecl}_{3}(\mathrm{w} / \mathrm{v})$ solution was added to $2 \mathrm{ml}$ of extract. Intense dark blue colour formation indicated the presence of phenols.

\section{Test for flavonoids}

$1 \mathrm{ml}$ of extract along with few drops of $\mathrm{NaOH}$ solution was added in test tube. Formation of intense yellow colour that became colourless on addition with few drops of dil. $\mathrm{Hcl}$ indicated the presence of flavonoids.

\section{Test for tannins}

$1 \mathrm{ml}$ of extract was taken and it was added with gelatin powder. Greyish white precipitate formations confirm the presence of tannins.

\section{Test for terpenoid}

Extract with $2 \mathrm{ml}$ acetic acid and $1 \mathrm{ml}$ sulfuric acid formed blue green ring at mid of the test tube which indicates the presence of terpenoid.

\section{Thin layer chromatography}

Analysis of phyto compounds in Thin layer chromatography

A thin layer of silica gel was spread on the glass plates; aqueous extract of curcubita maxima was applied as a small spot. The plate was placed in a trough containing the solvent. The stationary water phase is held on silica gel and mobile phase of non polar solvent moves up.

These chromatography gel were incubated at room temperature for 1 hour. After the solvent reaches $3 / 4^{\text {th }}$ of the chromatography paper it is taken out of the jar, the solvent front was drawn The gel was then kept in iodine jar for few seconds, shaken and taken out. They were examined under the UV/V is lamp and the spots were circled with pencil. The spots were labeled and the distances from the base lines were measured.

The Retention factor values were calculated by the formula,

$$
(\mathrm{RF})=\frac{\text { Distance travelled by solvent from origin }}{\text { Distance travelled by solute from origin }}
$$

\section{Result and Discussion}

Table 1, 2, 3 illustrate the presence of various nutrient in cucurbita maxima pulp. Table 4, 5 shows the phytochemical composition of the aqueous extract of cucurbita maxima pulp. The result shows that cucurbita maxima pulp extract nutrient contain carbohydrate, protein, fat, calcium, potassium, iron, Vit-A, Vit-C, Vit-E and phytochemical contain alkaloids, flavonoids, tanins, phenols, terpenoids. Phytochemical analysis conducted on the plant extracts revealed the presence of constituents which are known to exhibit medicinal as well as physiological activities. The protein and mineral compounds are one of the largest and most ubiquitous groups of plant metabolites. They possess biological properties such as antiapoptosis, antiaging, anticarcinogen, antiinflammation, cardiovascular protection and improvement of endothelial function. Several studies have described the antioxidant properties of medicinal plants which are rich in potassium and alkaloid compounds. 


\section{International Journal of Science and Research (IJSR) \\ ISSN (Online): 2319-7064}

Index Copernicus Value (2015): 78.96 | Impact Factor (2015): 6.391

Table 1: Estimation of Nutrient

\begin{tabular}{|c|c|}
\hline Nutrients & Amount in units \\
\hline Carbohydrate & $0.27 \mathrm{~g}$ \\
\hline Protein & $0.81 \mathrm{~g}$ \\
\hline Fat & $0.73 \mathrm{~g}$ \\
\hline
\end{tabular}

Table 2: Estimation of Minerals

\begin{tabular}{|c|c|}
\hline Nutrients & Amount in units \\
\hline Calcium & $10 \mathrm{~g}$ \\
\hline Potassium & $98.21 \mathrm{~g}$ \\
\hline Iron & $9.06 \mathrm{~g}$ \\
\hline
\end{tabular}

Table 3: Estimation of Vitamins

\begin{tabular}{|c|c|}
\hline Nutrients & $\begin{array}{c}\text { Amount in } \\
\text { units }\end{array}$ \\
\hline Vitamin C & $0.093 \mu \mathrm{g}$ \\
\hline Vitamin A & $0.116 \mu \mathrm{g}$ \\
\hline Vitamin E & $2.126 \mu \mathrm{g}$ \\
\hline
\end{tabular}

Table 4: Qualitative analysis of the phytochemicals in aqueous extract of cucurbita maxima pulp

\begin{tabular}{|c|c|}
\hline Phytochemicals & $\begin{array}{c}\text { Aqueous } \\
\text { extract }\end{array}$ \\
\hline Alkaloids & + \\
\hline Flavonoids & + \\
\hline Glycosides & - \\
\hline Tanins & + \\
\hline Terpenoids & + \\
\hline Phenols & + \\
\hline
\end{tabular}

Table 5: RF value phase in TLC using aqueous as solvent

\begin{tabular}{|c|c|}
\hline Phytochemicals & RF value \\
\hline Alkaloids & 0.88 \\
\hline Flavonoids & 0.84 \\
\hline Tanins & 0.46 \\
\hline Terpenoids & 0.66 \\
\hline Phenols & 0.38 \\
\hline
\end{tabular}

\section{Conclusion}

Cucurbita maxima pulp is good supplement of protein, vitamins, minerals, dietary fiber, anti-oxidant. It is one of the low calorie vegetable and cheaply available. It can be used by all the people in the society, irrespective of their economic status. The constituents of Cucurbita maxima pulp extracts may have several medicinal properties that leading to opening up new avenues in the use of natural products for therapeutic purpose. We wish to recommend the use of pumpkin pulp as a food additive so as to enhance the exploitation of the full potential of the plant.

\section{References}

[1] J. B. Harbrne, Phytochemical methods: A guide to modern techniques of plant analysis, third edition, London: Chapman and hall.1998:107-108

[2] O. H. Lowry protein measurement with the folinsphenol reagent .J Bio1 chem.193(1951) 265-275

[3] Brody T. (1994).Nutritional Biochemistry san Diego CA: Academic Press Ltd. 761-794

[4] WHO (1998).Quality control method for medical plant material. ISBN 9241545100(QV766)
[5] Dyana, J., And G. Kanchana, 2012.Preliminary phytochemical screening. International Journal of Current Pharmaceutical Research.4:62-63

[6] Praveen, K., S. Bhawana, 2013. HPLC Analysis and Isolation of Rutin from Stem Bark of Ginkgo biloba. Journal of pharmacognosy and phytochemistry;2(4):68-71 